\title{
Exploring the Learner's Perception about Embryology - Before and After Introduction of Competency Based Medical Curriculum (CBME)
}

Krishnaveni Sharath ${ }^{{ }^{*}}$, Rahe Rajan ${ }^{2}$, Durga Devi G ${ }^{3}$, WMS Johnson 4.

${ }^{* 1}$ Associate Professor, Department of Anatomy, Sree Balaji medical college and hospital, BIHER, Chrompet, Chennai, India.

${ }^{2}$ Associate Professor, Department of Anatomy, Sree Balaji medical college and hospital, BIHER, Chrompet, Chennai, India.

${ }^{3}$ Associate professor, Department of Anatomy, Sree Balaji medical college and hospital, BIHER, Chrompet, Chennai, India.

${ }^{4}$ Professor, Department of Anatomy, Sree Balaji medical college and hospital, Chrompet, BIHER Chennai, India.

\section{ABSTRACT}

Background: The perceived relevance of a subject/area will decide how much the student will study that. Competency based Medical Curriculum helps students to understand the subject relevance due to its structured format. The feedback from students about subject relevance is needed as they are the primary stakeholders for learning. In this era of involving molecular biology and genetics in medical field, it is very difficult to determine how much to teach a basic subject like embryology. This questionnaire study was done to know the viewpoints of $3^{\text {rd }}$ semester $\& 5^{\text {th }}$ semester medical students about the relevance and necessity of embryology in medical education.

Method: An anonymous questionnaire was sent to $3^{\text {rd }}$ semester, CBME batch $\& 5^{\text {th }}$ semester students, traditional or regular batch of Sree Balaji Medical College, Chrompet. The pre validated questionnaire contained questions regarding the perceived relevance \& importance of embryology.

Results: Students reported the relevance of embryology knowledge for learning other medical subjects \& they more often acknowledged embryology as being of great importance for their professional careers. This perception has increased especially after introduction of Competency based Medical Curriculum. Overall, study results suggest that medical students have a positive attitude toward embryology undergraduate course.

Conclusion: This evidence could be used as an additional motive for the development embryology courses, with special emphasis on practical application of knowledge in clinically-oriented setting.

KEY WORDS: CBME, perception, Relevance, Embryology, Medical teaching

Corresponding Author: Dr Krishnaveni Sharath, Associate Professor, Dept of Anatomy, Sree Balaji Medical College, Bharath Institute of Higher Education \& Research (BIHER) No 7, CLC Works road, Chrompet, Chennai 44, Tamil Nadu, India. E-Mail: drkrishna_veni@yahoo.com

\begin{tabular}{|c|c|c|c|}
\hline Access this Article online & \multicolumn{3}{|c|}{ Journal Information } \\
\hline \multirow[t]{3}{*}{ Quick Response code } & \multicolumn{3}{|c|}{$\begin{array}{l}\text { International Journal of Anatomy and Research } \\
\text { ISSN (E) 2321-4287 I ISSN (P) 2321-8967 } \\
\text { https://www.ijmhr.org/ijar.htm } \\
\text { DoI-Prefix: https://dx.doi.org/10.16965/ijar } \quad \text { (cc) Er-Nt-5i }\end{array}$} \\
\hline & \multicolumn{3}{|c|}{ Article Information } \\
\hline & $\begin{array}{l}\text { Received: } 01 \text { Dec } 2021 \\
\text { Peer Review: } 01 \text { Dec } 2021\end{array}$ & $\begin{array}{l}\text { Accepted: } 18 \text { Jan } 2 \\
\text { Published (O): } 051 \\
\text { Published (P): } 05 \mathrm{~N}\end{array}$ & $\begin{array}{l}2 \\
r 2022 \\
2022\end{array}$ \\
\hline
\end{tabular}

\section{INTRODUCTION}

Competency-based medical education (CBME) is an approach to preparing physicians for practice that is fundamentally oriented to graduate outcome abilities and organized around competencies derived from an 
analysis of societal and patient needs. It deemphasizes time-based training and promises greater accountability, flexibility, and learner-centredness. CBME involves the attainment of observable abilities by students in a time-independent, learner-centred manner. It is an approach to ensure that the graduates attain the competencies required to discharge their professional duties as health-care personnel. The emphasis is on outcomes that are relevant to the daily practice of medicine rather than facts. CBME provides an effective outcome-based strategy where various domains of teaching including teaching learning methods and assessment form the framework of competencies [1]. This was introduced by the Medical Council of India $(\mathrm{MCl})$, apex statutory body for establishing standards of medical education from the academic year 2019.

Embryology forms an integral part of the anatomy teaching in medical curriculums. Its learning outcomes have applications in general surgery, paediatrics, craniofacial surgery, obstetrics and gynaecology [2]. There are about 47 competencies related to embryology and about 10 competencies as Integration as given in Volume 1 of UG curriculum book by $\mathrm{MCl}$. The course of embryology is a mandatory field in the subject Anatomy during the 1st year for medical students in India. It is taught throughout the year, approximately 1 hour per week, non continuously in both semesters. It is usually taken as lectures or in small group teaching, with no practical hour being allotted. The plan and program of medical teaching is accredited by the Medical council of India.

The fundamental intellectual reason for studying embryology is to understand how our bodies came into being. As with most other basic science disciplines, this can be viewed as the acquisition of knowledge for its own sake, but behind that there are several reasons why this knowledge is important. Birth defects continue to rank high among the conditions that bring people to their doctors. Medical embryology has traditionally covered not only normal human development but defective development, as well. Another important function of embryology is to provide a logical basis for understanding the overall organization of the human body [3]. Embryology remains an important tool in medicine and surgery for the management of many clinical conditions. As a subject, it is neither straightforward nor easy to learn and teach in a busy modern medical school curriculum and can be easily overlooked. Embryology has progressed from an observational science to one involving sophisticated technological and modern molecular advances. The better understanding of embryology has resulted in newer and better techniques for prenatal diagnosis and treatment and mechanisms to prevent birth defects [4]. Like any other subject, embryology must justify its place in an increasingly crowded medical curriculum [3]. Embryology finds itself jostling for precious space in the crowded medical curriculum, yet remains important for helping students understand birth defects [5].

Against a backdrop of ever-changing diagnostic and treatment modalities, medical student's perceptions, are crucial for the design of an anatomy curriculum which fulfils the criteria required for safe medical practice [6]. The students are usually never involved in the planning or revising of the curriculum. It is therefore necessary to know the views of the students while revising the curriculum and to know the best teaching methodology which will facilitate the learning process [7].

The study aimed to determine the attitude of MBBS students towards importance of embryology before and after rolling of CBME.

\section{MATERIALS AND METHODS}

This cross sectional study was conducted among student participants, grouped according to their semesters. Group A consisted of 3rd semester students who were taught embryology as per CBME \& $5^{\text {th }}$ semester MBBS students, who were taught embryology traditionally of Sri Balaji Medical College, Chennai. The institutional ethical clearance was obtained for the study. Both the groups were briefed about the study and were instructed that the response must be unbiased 
and data will be anonymous. The questions were validated $\&$ the questionnaire was shared among both the groups. Informed consent to participate in the study was taken. The questionnaire was designed to investigate perceptions of relevance of embryology curricula to the modern medical curriculum as well as current medical practice based on the following survey domains.

a) Level of agreement with statements concerning the role of embryology in the medical curriculum and its relevance to clinical practice (Likert's scale).

b) Ranking of usefulness of learning embryology, in terms of perceived importance, of various subjects (open closed question)

c) The time students takes to study embryology and why (open question)

The results obtained were analysed using SPSS version 19.

\section{RESULTS}

The questionnaire was sent to all students of $3^{\text {rd }}$ and $5^{\text {th }}$ semester. In group A ( $3^{\text {rd }}$ semester students) 196 responses were obtained and in group B ( $5^{\text {th }}$ semester students) 168 responses were obtained. The mean age of students in group A was 20.1 with $52.4 \%$ females. It was 22.8 in Group B with $56.4 \%$ females.
In both the groups, students perceived embryology to be relevant to learning anatomy, learning other subjects and clinical practice as seen in table 1.

The students of both groups perceived the relevance of embryology in learning other subjects both horizontally - Physiology \& Biochemistry and vertically - paediatrics, surgery, Medicine, obstetrics \& gynaecology etc. Graph 1 shows the perceived importance of embryology (in percentage) for other subjects both horizontally (Physiology \& Biochemistry) and vertically (like surgery, ObG, Paediatrics and medicine).

Most of the Group A students studied embryology for a lesser time as the marks allotted for the same was low and they could not squeeze it in, though the perceived importance was high. In Group B most students, felt they could remember embryology better as it was taught in a structured manner and with a problem based approach. The objectives of the relevant topic made them aware of the 'must know' areas and plan their time accordingly.

Table 1: Perceived relevance of embryology by the group of students.

\begin{tabular}{cccc}
\hline & $\begin{array}{c}\text { Relevance in learning } \\
\text { anatomy } \\
\text { (strongly agree or agree) }\end{array}$ & $\begin{array}{c}\text { Relevance in learning other } \\
\text { subjects }\end{array}$ & $\begin{array}{c}\text { Relevance in clinical } \\
\text { practice }\end{array}$ \\
\hline Group A & $82.60 \%$ & $62.80 \%$ & $\begin{array}{c}\text { (strongly agree or agree) } \\
\text { (strongly agree or agree) }\end{array}$ \\
\hline Group B & $84.20 \%$ & $70.10 \%$ & $59.60 \%$ \\
\hline
\end{tabular}

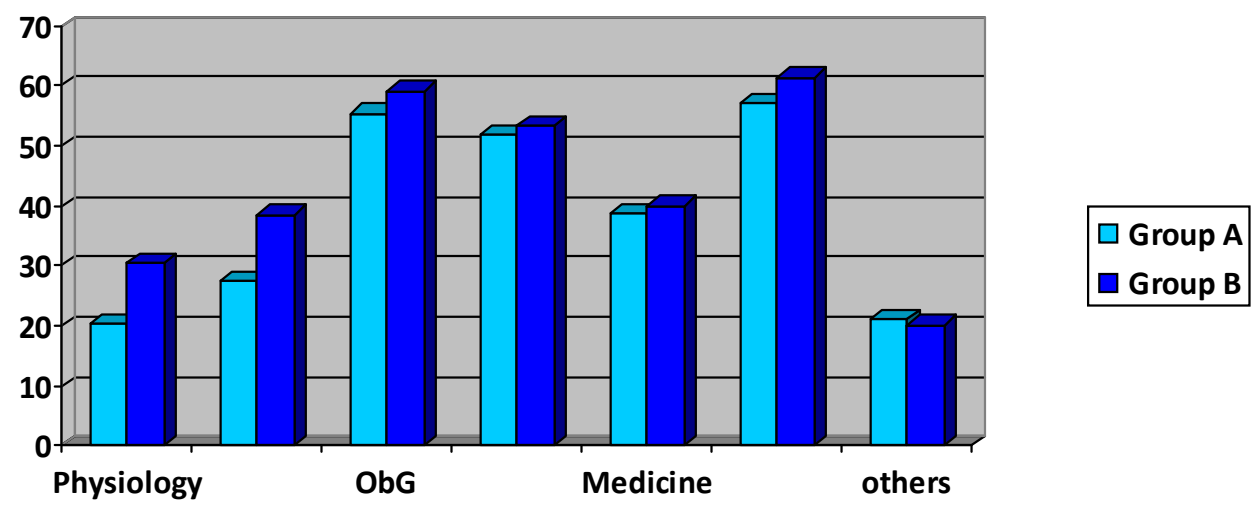

Graph 1: Percieved importance of embryology for other subjects. 


\section{DISCUSSION}

This study was done to analyse the perceptions of students about embryology and its clinical relevance before and after introduction of CBME. The study is unique in the aspect that it takes the perception of the students who have completed the $1^{\text {st }}$ year MBBS course and hence unlikely to be biased to please the teachers.

Feedback from the learners, who are the important stakeholders, is an important tool in 'Need assessment' and 'program evaluation' $[8,9]$. It serves as a useful basis for modifying $\&$ and improving medical education. Through feedback we can also identify areas of strength and/or weakness of teaching methodology used so that steps can be taken to rectify deficiencies and to evolve the curriculum and achieve intended goal.

In the study the students of both groups understand and feel the relevance of embryology and the percentage of the same is more in Group B students who are in $5^{\text {th }}$ semester. This is seen in many other studies as well where the students of senior years perceive embryology to be more relevant than the $1^{\text {st }}$ year MBBS students. Breaking of competency into 'specific learning objective' in CBME enables the student to understand the relevance of the subject. The perceptions of the students in CBME can also be influenced by the fact that it emphasizes on small groups - enhancing peer learning and introduction of Problem based learning [10].

The results of the study showed that $68.7 \%$ of students after introduction of CBME (Group B) feel that embryology is highly relevant for clinical practice \& $70.1 \%$ feel it is relevant for further medical studies. It is in contrast to Group A students where only $59.6 \%$ felt it relevant for clinical practice and $62.8 \%$ felt its relevance to other medical subjects. This is definitely due to the introduction of vertical \& horizontal integration \& Early Clinical exposure (ECE) [11]. The Group B students exposed to CBME curriculum, incorporating ECE making learning \& understanding the subject better. Vertical \& horizontal integration is emphasized in CBME and has a definite role in understanding the relevance of embryology in clinical practice $[12,13]$.

In many studies it is observed that students also do not concentrate on embryology to the extent they do for gross anatomy. The time and marks allotted for Embryology within Anatomy is less. Most of them do not even read the must know portions in embryology. The inadequate knowledge of embryology has been attributed to embryology being incorporated into gross anatomy courses [3]. Frequent embryology viva at least once a month would ensure that they do update their knowledge in this. Demonstration of certain topics like rotation of gut by a plastic pipe, role play to show the parts of uterus would go a long way in retaining the topics [14].

It will be better if embryology lectures are replaced with required preclass readings, self-assessment quizzes, small group discussions of assignments, and groups retaking the same quizzes for deeper learning. Problem based learning (PBL), where students use "triggers" from the problem case or scenario to define their own learning objectives is most commonly used in CBME \& has shown a very favourable response for team based and problem based learning in embryology. Presentation of clinical material as the stimulus for learning enables students to understand the relevance of underlying scientific knowledge and principles in clinical practice $[15,16]$.

Innovative methods used in different Universities like including digital documentation of embryos, foetuses and neonates undergoing autopsy and shown to the students, who were also encouraged to find and discuss the malformations and their clinical history, diagnosis and therapeutics. Another was to divide the students into groups from five to seven who used textbooks \& prepared models under teacher's guidance. These methods were not only appreciated by students but their grades also were improved. These and other innovative methods have to be tried in our settings as well to facilitate a smooth learning and teaching of embryology. Flipped classes and introduction of learning management system may be of great help in teaching 
embryology $[14,17]$.

Clearly, embryology has a significant part to play in medical education in terms of understanding prenatal life, of appreciating how the organization of the mature human body has developed, and of providing essential information for general medical practice, obstetrics and paediatrics, and teratology. However, while newly recruited medical students understand the importance of gross anatomy in the development of professional competence, understanding the importance of embryology requires teachers, medical educationalists, and devisors of medical curricula to pay special attention to informing students of the significant role played by embryology in attaining clinical competence and achieving the knowledge and understanding of the biomedical sciences that underpins becoming a learned member of a health care profession [18].

Bearing in mind the results from our study, we conclude that medical students have positive attitude toward the embryology undergraduate course especially after the introduction of CBME. After completing their exam in anatomy, students were able to use the acquired embryology knowledge for successful mastering and understanding of other medical subjects, such as physiology, pathology, ObG, paediatrics and surgery. This evidence could be used as an additional motive for further development of embryology courses, where a special emphasis should be put on practical application of knowledge in a clinically-oriented setting. The newly introduced competency based medical education curriculam may provide further positive approach in teaching and learning anatomy.

\section{CONCLUSION}

Our results underline the relevance of embryology in daily professional activity as perceived by the students especially after the introduction of CBME who are the main stakeholders. Evidence-based studies such as ours lend greater credibility and objectivity to the role of embryology in the undergraduate training of health professionals and should help to establish a more appropriate curriculum for future professionals.

Competing interests: The authors declare they do not have any competing interests

\section{Authors Contribution}

Krishnaveni Sharath - Preparation of questionnaire, collection of data, data analysis and interpretation, article writing.

https://orcid.org/0000-0001-7714-5804

WMS Johnson - Conceptualization of the study design, preparation of questionnaire, collection of data, article proof reading and critical analysis.

https://orcid.org/0000-0002-2522-3783

Rahe Rajan - Conceptualization of study design and methodology, collection of data, article writing. https://orcid.org/0000-0002-0487-0412

Durga Devi G - Refining the study method, collection of data, data interpretation, article proofreading and critical analysis.

https://orcid.org/0000-0003-1852-8711

\section{ACKNOWLEDGEMENTS}

The authors would like to acknowledge the MEU department of Sree Balaji Medical College, for their ideas and help in the study.

\section{REFERENCES}

[1]. MCl. Competency based Undergraduate curriculum for the Indian Medical Graduate, 2018. Vol. 1; pg 20. Available from: https://www.nmc.org.in/ wp-content/uploads/2020/01/UG-Curriculum-VolI.pdf

[2]. Zaletel I, Mariæ G, Gazibara T, Rakoèeviæ J, Labudoviæ Boroviæ M, Puškaš N, et al. Relevance and attitudes toward histology and embryology course through the eyes of freshmen and senior medical students: Experience from Serbia. Ann Anat - Anat Anzeiger. 2016 Nov;208:217-21.

[3]. Carlson BM. Embryology in the medical curriculum. Anat Rec. 2002 Apr 15;269(2):89-98.

[4]. Hamilton J, Carachi R. Clinical embryology: is there still a place in medical schools today? Scott Med J. 2014 Nov;59(4):188-92.

[5]. Scott KM, Charles AR, Holland AJA. Clinical embryology teaching: Is it relevant anymore? ANZ J Surg. 2013;83(10):709-12.

[6]. Sbayeh A, Qaedi Choo MA, Quane KA, Finucane P, McGrath D, O'Flynn S, et al. Relevance of anatomy to medical education and clinical practice: perspectives of medical students, clinicians, and educators. Perspect Med Educ. 2016;5(6):338-46.

[7]. Jaiswal R, Sathe S, Gajbhiye V, Sathe R. Students Perception on Methods of Anatomy Teaching and Assessment. Int J Anat Res. 2015;3(2):1103-8.

[8]. Grant J. Learning needs assessment: assessing the need. BMJ Br Med J [Internet]. 2002 Jan 19 [cited 2021 Nov 27];324(7330):156. Available from: / pmc/articles/PMC64520/ 
[9]. Mandouit L. Using student feedback to improve teaching. Educ Action Res. 2018;26(5):755-69.

[10]. Frank JR, Snell LS, Cate O Ten, Holmboe ES, Carraccio C, Swing SR, et al. Competency-based medical education: theory to practice. https://doi.org/ 103109/0142159X2010501190 [Internet]. 2010 Aug [cited 2021 Nov 27];32(8):638-45. Available from: https://www.tandfonline.com/doi/abs/ 10.3109/0142159X.2010.501190

[11]. Sheshgiri C, Komala N, Ashwini CA. Early Clinical Exposure In Anatomy. Natl J Integr Res Med [Internet]. 2017;8(5):53-7. Available from: https:/ /www.researchgate.net/profile/Ashwini_Appaji/ publication/321936939_Early_Clinical_Exposure_ In_Anatomy/links/5a39̄de97aca2728e-69879e30/ Early-Clinical-Exposure-In-Anatomy.pdf

[12]. Ramanathan R, Shanmugam J, Gopalakrishna S, Palanisami K, Narayanan S. Exploring the learners' perspectives on competency-based medical education. J Educ Health Promot [Internet]. 2021 Jan 1 [cited 2021 Dec 1];10(1):109. Available from: https://www.jehp.net/article.asp?issn $=2277$ 9531; year=2021; volume=10; issue=1; spage=109; epage=109; aula st=Ramanathan

[13]. Dulloo P, Vedi N, Gandotra A. Impact of horizontal and vertical integration: Learning and perception in first-year medical students. Natl J Physiol Pharm Pharmacol [Internet]. 1170 [cited 2021 Nov 27];11. Available from: www.njppp.com
[14].Aversi-Ferreira TA, Aversi-Ferreira RAGMF, Do Nascimento GNL, Nyamdavaa E, Araujo MF, Ribeiro $\mathrm{PP}$, et al. Teaching Embryology Using Models Construction in Practical Classes. Int J Morphol. 2012;30(1):188-95.

[15]. Wood DF, F. D. ABC of learning and teaching in medicine: Problem based learning. BMJ. 2003 Feb;326(7384):328-30.

[16]. Yogesh M, Viveka S, Sudha MJ, Kurugod S, Udyavar A. Integration of Problem Based Learning with Conventional Teaching for Understanding Anatomy among First Year Medical Students. Int J Heal Sci Res [Internet]. 2013;3(December):99-104. Available from: http://www.scopemed.org/ fulltextpdf.php?mno=49561

[17]. Antonio Violin Pereira L, Guimarães Moraes S, Vidigal de Andrade Reis M, Fernando Santos Mello $\mathrm{M}$, Antônio Violin Pereira L. Autopsies as a tool for teaching embryology The usefullness of autopsies as a tool for teaching human Embryology. Braz J morphol Sci. 2004;21(3):117-23.

[18]. Golshani N, Mehraban B, Rashidi I, Salari N, Jalili C. Factors Affecting Anatomy Learning from the Viewpoints of Medical Students at Basic Sciences Stage. Educ Res Med Sci. 2018; In Press(In Press).

How to cite this article:

Krishnaveni Sharath, Rahe Rajan, Durga Devi G, WMS Johnson. Exploring the Learner's Perception about Embryology - Before and After Introduction of Competency Based Medical Curriculum (CBME). Int J Anat Res 2022;10(1):82448249. DOI: 10.16965/ijar.2021.195 